\title{
Rhinoplasty and its effects on the perception of beauty
}

\author{
Hernan Chinski', Luis Chinski², Jenny Armijos ${ }^{3}$, Juan Pablo Arias ${ }^{3}$. \\ 1) Medical doctor (staff physician, Rhinology and Facial Plastic Surgery, ENT Department, University of Buenos Aires, Argentina) \\ 2) Medical doctor (staff physician, ENT, Head and Neck Surgery, University of Buenos Aires, Argentina) \\ 3) Medical doctor (resident, ENT Department, University of Buenos Aires, Argentina) \\ Please send correspondence to: Hernan Chinski \\ ENT Department, Hospital de Clinicas, University of Buenos Aires, Buenos Aires, Argentina \\ Charcas 2777 ro A \\ Article received on August 4, 2012. Article accepted on October 7, 2012.
}

\section{SUMMARY}

Introduction: Experts on nasal cosmetics and nasal surgery agree that aesthetic rhinoplasty leads to overall facial beautification and the perception of youth in patients. This "assumed truth" has never been proven in the international literature.

Aim: To examine increases in facial attractiveness ratings after rhinoplasty surgery.

Methods: We conducted a study series by choosing 30 female patients on whom we had operated and 25 evaluators in a single blind trial. The evaluators graded the patients' attractiveness before and after surgery.

Results: Beauty indices were significantly improved after the operation.

Conclusion: According to the third-party evaluation, the patients appeared prettier after undergoing aesthetic rhinoplasty. Keywords: rhinoplasty, beauty, perception.

\section{INTRODUCTION}

Rhinoplasty is an existing surgical practice intended to return nasal harmony to a patient. Surgeons assume that patients will look prettier and younger after the operation. This statement may appear obvious, but the international literature contains no statistical study that proves this.

The aim of our work was to prove that impartial evaluators' perception of the beauty and youth of patients aged 25-50 years would increase after the patients had undergone primary rhinoplasty. Our results are statistically significant.

\section{METHOD}

The present study included 30 patients who had undergone primary rhinoplasty at Hospital de Clinicas and the CECHIN otolaryngology centre in Buenos Aires, Argentina, between 2009 and 2011.

We used facial photographs of the patients, including front, profile, and $3 / 4$ angles. The recruited patients had typical defects such as nose tip drop and nasal dorsum hump. All cases involved open rhinoplasties using redistributive and non-resective techniques (1).

Photographs were obtained before and after (at least 6 months) each patient's operation. All photographs were obtained by the same person with the same camera in identical light conditions, the same setting, and from the same perspective and distance.

The photographs were loaded onto Microsoft PowerPoint slides (2 displayed per patient, one preoperative and one postsurgical). Each slide displayed 3 photographic angles (front, profile, and 3/4) (Figure 1).



Figure 1. Example of patient used in the study. Top photograph is pre-operative. Bottom photograph is post-operative. Note that the subject is pictured from the front, 3/4, and profile angles. 




Figure 2. Distribution of patients in 2 groups of 30 slides each. Each slide in the group exhibits pre-operative and post-operative patient pictures captured from the front, 3/4, and profile angles.

\begin{tabular}{|c|c|c|c|c|c|c|c|c|c|c|c|}
\hline Group A & & & Group B & & & Group A & & & Group B & & \\
\hline Order\# & Patient \# & Condition & Order \# & Patient \# & Condition & Order \# & Age & Beauty & Order \# & Age & Bequty \\
\hline 1 & 3 & pre & 1 & 25 & post & 1 & 23 & 7 & 1 & 50 & 6 \\
\hline 2 & 10 & post & 2 & 4 & pre & 2 & 3 L & 6 & 2 & 24 & $y$ \\
\hline 3 & 20 & post & 3 & 3 & post & 3 & $2 y$ & 8 & 3 & 25 & 7 \\
\hline 4 & 6 & pre & 4 & 15 & pre & 4 & 30 & 5 & 4 & 2 & 3 \\
\hline 5 & 23 & pre & 5 & 24 & pre & 5 & 30 & 4 & 5 & 26 & 8 \\
\hline 6 & 14 & pre & 6 & 6 & post & 6 & 35 & 3 & 6 & 32 & 7 \\
\hline 7 & 24 & post & 7 & 14 & post & 7 & 28 & 8 & 7 & 36 & 6 \\
\hline 8 & 30 & pre & 8 & 10 & pre & 8 & & 2 & 8 & 24 & \pm \\
\hline 9 & 1 & post & 9 & 8 & pre & 9 & 2 & 9 & 9 & & 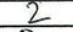 \\
\hline 10 & 9 & post & 10 & 26 & pre & 10 & 27 & 7 & 10 & 50 & 3 \\
\hline 11 & 27 & pre & 11 & 17 & pre & 11 & 34 & 5 & 11 & 30 & 4 \\
\hline 12 & 11 & pre & 12 & 18 & post & 12 & 3 & 6 & 12 & 26 & 8 \\
\hline 13 & 4 & post & 13 & 11 & post & 13 & 8 & 7 & 13 & 24 & 9 \\
\hline 14 & 18 & pre & 14 & 13 & pre & 14 & 24 & 6 & 14 & 32 & $f$ \\
\hline 15 & 21 & pre & 15 & 27 & post & 15 & $y_{1}$ & 4 & 15 & 38 & 7 \\
\hline 16 & 17 & post & 16 & 21 & post & 16 & 32 & 5 & 16 & 50 & 5 \\
\hline 17 & 13 & post & 17 & 20 & pre & 17 & 30 & 8 & 17 & $S$ & $F$ \\
\hline 18 & 5 & pre & 18 & 2 & post & 18 & 3 & 4 & 18 & 26 & 7 \\
\hline 19 & 19 & post & 19 & 28 & pre & 19 & 28 & 7 & 19 & 42 & $z$ \\
\hline 20 & 12 & pre & 20 & 19 & pre & 20 & 36 & 4 & 20 & & \\
\hline 21 & 22 & post & 21 & 29 & post & 21 & 30 & 6 & 21 & & 6 \\
\hline 22 & 25 & pre & 22 & 7 & pre & 22 & 75 & $y$ & 22 & 33 & 2 \\
\hline 23 & 7 & post & 23 & 5 & post & 23 & 50 & 6 & 23 & 28 & $y$ \\
\hline 24 & 29 & pre & 24 & 12 & post & 24 & & $y$ & 24 & 38 & 7 \\
\hline 25 & 15 & post & 25 & 22 & pre & 25 & 25 & 8 & 25 & 30 & 7 \\
\hline 26 & 16 & pre & 26 & 30 & post & 26 & $2 L$ & $y$ & 26 & 50 & 6 \\
\hline 27 & 28 & post & 27 & 23 & post & 27 & 39 & 6 & 27 & 22 & 7 \\
\hline 28 & 8 & post & 28 & 9 & pre & 28 & 38 & 4 & 28 & 29 & 3 \\
\hline 29 & 2 & pre & 29 & 1 & pre & 29 & 30 & $\frac{b}{b}$ & 29 & 22 & 6 \\
\hline 30 & 26 & post & 30 & 16 & post & 30 & 50 & 6 & 30 & 26 & 4 \\
\hline
\end{tabular}

Figure 3. A table (left) displaying the random patient distribution in 2 groups in pre-operative or post-operative order. A scan of the survey conducted by an evaluator (right).

Groups of 30 slides were assembled, with each pair of photographs randomly distributed into pre-operative (A) and post-operative (B) groups (see Figure 2), thus ensuring no photograph was exhibited twice in the same group.

The slides were displayed using Microsoft Excel's randomization system (Figure 3, left).

We recruited 25 medical students to perform the evaluations, but did not divulge the reason for the evaluation. They were asked to participate voluntarily, and received no monetary compensation. The students were shown consecutive pictures from groups A and B (Figure 4). After viewing each slide for 10 seconds, the students scored each photograph for (1) facial attractiveness according to a visual analogue scale $(1-10 ; 1=$ very ugly, $10=$ very beautiful). Age also was ranked, with the evaluators asked to note the suspected age of the person in each photograph. Students were told that they would view repeat pictures but that the repetition would be random. Viewing more than 60 slides, we assumed it would be highly unlikely that the evaluators would remember the scores they had given to specific subjects previously. The students were not informed that the nose of the patients in the photographs had been altered surgically, nor was any other information provided. The data were recorded on tables designed especially for this study (see Fig. 3, right). 


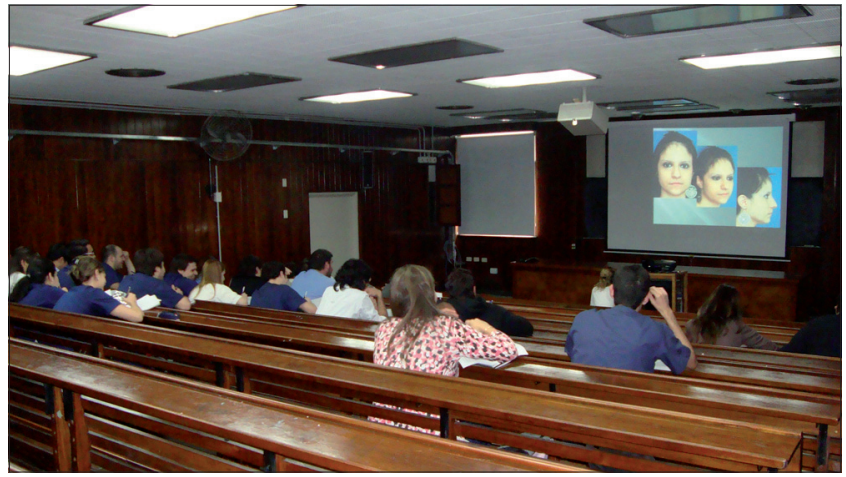

Figure 4. Photograph of evaluation period; note slide projection and evaluator note taking.

The aim of this study was to evaluate data and verify significant differences between scores before and after the surgery.

In the present study, we posed the following hypotheses: (1) rhinoplasty has positive effects on beauty; the post-rhinoplasty beauty index is higher than the prerhinoplasty index, and (2) rhinoplasty significantly decreases perceived age.

\section{RESULTS}

All included parameters were inserted into an Excel table: one table per presentation. Following the introduction of each set of patient and variable data, we compiled a database with SPSS (Statistical Package for the Social Sciences, version 2.0). Tables 1 and 2 list the averaged results, including pre-operative and post-operative standard deviation and error.

The average pre-operative beauty ranking on a visual analog scale of $1-10$ was 5.38 , whereas the postoperative beauty ranking was 5.79 . The average age guessed for individuals in pre-rhinoplasty photographs was 30-31 years, whereas the average post-rhinoplasty age guessed was 24-30 years. $\mathrm{P}=0.001$ was established for improved facial beauty and $\mathrm{P}=0.830$ for the appreciation of age.

\section{DISCUSSION}

Facial beauty perception has been studied broadly over the past decades (2). Studies on facial proportionality indicate its influence on the perception of beauty (3).

Certain studies have evaluated beauty after treatments such as nasal reconstruction (4) and orthodontics (5). Fan et al. studied physical attractiveness in women
Table I. Survey results (average).

\begin{tabular}{ccccc}
\hline & \multicolumn{2}{c}{ Pre-operative } & \multicolumn{2}{c}{ Post-operative } \\
Patient & Age & Beauty & Age & Beauty \\
\hline 1 & 23,48 & 6,44 & 21,6 & 8,04 \\
2 & 27,44 & 5,08 & 26,84 & 6,04 \\
3 & 30,16 & 5,8 & 32,32 & 5,6 \\
4 & 26,96 & 4,92 & 27,4 & 4,36 \\
5 & 26,68 & 6,12 & 26,12 & 6,56 \\
6 & 30,72 & 5,76 & 29,76 & 6,24 \\
7 & 28,96 & 6,56 & 28,52 & 5,92 \\
8 & 37,24 & 4,2 & 38,36 & 5,8 \\
9 & 25,68 & 6,8 & 27,24 & 5,2 \\
10 & 27,64 & 4,8 & 27,8 & 5,64 \\
11 & 24,36 & 5,72 & 24 & 6,24 \\
12 & 36,96 & 5,16 & 35,24 & 5,32 \\
13 & 30,04 & 4,44 & 34,08 & 5,56 \\
14 & 28,08 & 4,8 & 29,56 & 5,72 \\
15 & 28,56 & 6,36 & 28,2 & 5,6 \\
16 & 25,84 & 5,08 & 25,4 & 5,72 \\
17 & 30,96 & 5,72 & 30,2 & 6,08 \\
18 & 25,84 & 5,12 & 25,32 & 5,64 \\
19 & 27,56 & 5,16 & 27,96 & 5,28 \\
20 & 23,44 & 7,08 & 26,16 & 8,16 \\
21 & 39,88 & 5,88 & 39,92 & 6,16 \\
22 & 28,88 & 5,08 & 28,44 & 5,36 \\
23 & 27,76 & 4,2 & 25 & 5,64 \\
24 & 26,04 & 5,84 & 26,44 & 6,04 \\
25 & 41,36 & 5,64 & 39 & 5,96 \\
26 & 38,12 & 4,4 & 38,8 & 5,2 \\
27 & 29,88 & 4,8 & 30,6 & 5,8 \\
28 & 36,88 & 5,2 & 36,96 & 5,72 \\
29 & 27,6 & 4,4 & 26,56 & 4,52 \\
30 & 46,36 & 4,72 & 43,4 & 4,72 \\
\hline & & & &
\end{tabular}

Table 2. Survey results (averages, and standard deviation and error).

\begin{tabular}{lcccc}
\hline Variabel & Group & Averange & StandarDeviation & Standarderror \\
\hline Beauty & Pre & 5,38 & 1,585 & 0,058 \\
& Post & 5,79 & 1,607 & 0,059 \\
Age & Pre & 30,31 & 6,615 & 0,242 \\
& Post & 30,24 & 6,364 & 0,232 \\
\hline
\end{tabular}

based on the body mass index; slim women were deemed more attractive (6). Most studies have used a visual analog scale from $1-10(1=$ not pretty; $10=$ very pretty $)(7-9)$.

Several studies also have evaluated patient satisfaction and self-perception of beauty, but these types of efforts do not match the assessment of an external observer. Prior studies have not evaluated primary rhinoplasty outcomes in terms of beauty, nor has perceived age been evaluated. After undergoing rhinoplasty, most patients appear much younger. 
Our team studied the effects imparted by rhinoplasty on the perception of facial beauty (i.e., that patients' faces would appear more attractive after the operation). We wish to highlight that the surgery is performed only on the nose; however, the face as a whole ultimately looks more attractive.

Certain studies have shown that a person focuses on the eyes, mouth, and ears when meeting someone for the first time; in the presence of an aesthetic facial defect, the individual focuses on the defect or asymmetry. Weunderstand that a natural outcome of rhinoplasty is that a patient is viewed as being prettier overall based on holistic perception of the face, and not only from having a prettier nose.

Regarding age, we were amazed to discover a lack of significant differences regarding perceived patient age pre-rhinoplasty and post-rhinoplasty. We believe inherent rejuvenation occurs due to rhinoplasty, but this was not reflected in this study. For future studies, we believe that 3 variables should be corrected to prove the influence of rhinoplasty on the perception of age: (1) use an older group of patients for whom rhinoplasty would create a greater difference in the perception of age, (2) photograph post-operative patients within 2-6 years after surgery, and 3) enroll patients with nasal tip drop because the rejuvenation effect is far greater than in cases corrected by descendant rotation. We will make these adjustments in future studies.

\section{CONCLUSION}

This study proved that patients who have undergone rhinoplasty appear more beautiful.

We conclude that rhinoplasty influences facial beauty positively and in a statistically significant manner. With regard to age, we observed a rejuvenation effect.

\section{REFERENCES}

1. Chinski H, Chinski L. "Rinoplastía Redistributiva Vs. Rinoplastía Resectiva. Cambio de paradigma en la cirugía de Rinoplastía" Revista de la Federación Argentina de Sociedades de Otorrinolaringología. Año 17. N1. Año 2010.

2. Marck S. Nestor, Subjetive and Objective Facial Attractiveness Ratings and Gender Differences in Objective Appraisals of Female Faces. The Journal of Clinical and Aesthetic. 2010;121:31-35.

3. Raymond E, Pragaty A. The use of anthopometric proportion indices in the measurement of facial attractiveness. European Journal of Orthodontics. 2006:28;274-281.

4. Sanne E. Moolenburgh. Aesthetic outcome after nasal reconstruction: patient versus panel perception. Journal of Plastic, Reconstrucive Aesthetic Surgery. 2008;61:14591464 .

5. Mirjam H, Gernot G. The Ideal of Facial Beauty: A Review. Journal of Orofacial Orthopedics. 2007;68:6-16.

7. J. Fan, F. Liu, J. Wu and W. Day. Visual Perception of female physical attractiveness. The Royal Society. 2004;271:347-352.

8. R.M.A Kiekens. Influence of Panel Composition on Aesthetic Evaluation of Adolecent Faces. 2007;29:95-99.

9. Yosh Jefferson. Facial Beauty Establishing a Universal Standard. 2004;15:9-20.

10. Zlatko Devcic, Koohyar K. A Web Based Method for Rating Facial Attractiveness. The Laryngoscope. 2010;120:902-906. 